\title{
Working towards culturally sensitive ethical practice in a multicultural society
}

\section{Zita Weber ${ }^{1}$}

Summary: In the last two decades there has been a lot of theorising about multiculturalism and professional practice. Many practitioners are challenged by cultural diversity daily. Practising from a culturally sensitive ethical perspective in a multicultural society is essential for good practice. Postmodern influences and critical questioning are seen to inform culturally sensitive ethical practice in their encouragement of practitioners' adoption of multiple belief systems and multiple perspectives and the need to pose questions challenging practice regarding awareness of cultural encapsulation and cultural sensitivity. The development of culturally sensitive ethical practice guidelines within the context of a multicultural society is proposed, firstly, by assessing the cultural sensitivity of the ethics codes and secondly, by balancing culture and ethical codes.

Key words: professional practice, cultural competence, ethics, cultural diversity, multiple perspectives, respect

\section{Lecturer in Social Work Practice}

Address for Correspondence: School of Social Work and Policy Studies, The University of Sydney, Education Building, Sydney, NSW 2006, Australia. z.weber@edfac.usyd.edu.au 
In the last two decades, there has been a lot written about multiculturalism and professional practice (Diaz-Lazaro and Cohen, 2001; Dominelli, 1988; Ivey, 1987; Ivey, Ivey and Simek-Morgan, 1997; Johnson, 1989; Ivey, Pedersen and Ivey, 2001; Nguyen and Bowles, 1998; Pedersen, 2000; Sue and Sue, 1977; Sue and Sue, 2003; Thompson, 1997; Wohl, 1989). Many of us are challenged by cultural diversity daily. Of late, some literature has explored the heightened awareness of the importance of cultural considerations in practice and the realisation that culturally competent practice and ethical decision-making need close reflection (Goldberg, 2000; Ivey, Pedersen and Ivey, 2001; Pack-Brown, Whittington-Clark and Parker, 1998; Pack-Brown and Williams, 2000; Pack-Brown and Williams, 2003).

My own thinking has become sharper over time. Because I'd been a migrant child, I always believed I had some real understanding and a deep level of empathy for cultural differences and sensibilities. However, over the years, I've discovered how much I had to learn about the realities of working with cultural diversity.

Teaching social work students at both undergraduate and graduate levels in Australia, a country recognised as comprising many different languages, cultural traditions and ethnic origins, I'm confronted by cultural sensitivity and competence issues and the ever-present ethical issues and dilemmas.

\section{Post modern influences}

Working towards culturally sensitive ethical practice presupposes a post modern stance (Christopher, 1996; Sue et al., 1996), and a move away from epistemological assumptions that are not necessarily shared across cultures. Such a stance entertains the existence of multiple belief systems and multiple perspectives (Gonzalez, 1997; Highlen, 1996; Sue et al, 1996). For instance, culturally sensitive practice would accept the existence of multiple worldviews and reinforce the notion that such worldviews are neither 'good or bad' nor 'right or wrong'. The refutation of this 'either or' view endorses the validity of each worldview and reinforces cultural relativism by recognising that each culture and attendant worldview is unique and can only be understood in itself and not by reference to any other culture and attendant worldview.

41 Journal of Practice Teaching 5(3) 2004, pp.40-54 @ 2004. Whiting and Birch 
Socio-politically, this stance is important as it inherently recognises the unfairness of one group imposing its standards on another.

Postmodernism also would inform the practitioner working towards culturally sensitive ethical practice that language does not equal 'perception of reality'. Adopting a relational view of language allows the practitioner to look beyond the truths and realities of the dominant culture as enshrined in language, both oral and written. Language and conceptual constructions vary tremendously between cultures. The importance of sensitivity to language and the way in which it is used may be illustrated in the encounter where the practitioner is using language and formulating questions from their cultural perspective regarding mental health concerns and the client is viewing the concerns from their different worldview. Such a situation is exemplified by Tsui and Schultz (1985) who write,

The therapist must explicitly educate the client about the purpose of questions regarding clinical history, previous treatment information, family background and psychosocial stressors. The linkage of these issues to their current symptoms is not clear to many Asian clients. Many Asian clients conceive of mental distress as the result of physiological disorder or character flaws. This issue must be dealt with sensitively before any sensible therapeutic work can be effected. (pp.567-568)

Similarly, it is important to take into consideration cultural nuances of nonverbal cues as different cultural groups ascribe varied meaning to certain nonverbal behaviour. Eye contact, for instance, is expected among persons communicating in mainstream English-speaking cultures (Australia, Britain, USA, Canada). Certain stereotypes have developed regarding evasiveness and untrustworthiness of those people who avoid direct gazing. However, it is now well known that in some cultures, direct eye contact is regarded as disrespectful and an invasion of privacy. I experienced this cultural nuance when teaching in Texas where some Mexican-American students employed minimal eye contact with me. When I enquired about this, it was explained that as a older person in position of authority, it would be disrespectful to look me directly in the eye.

Failing to understand the significance of nonverbal behaviour may pose barriers to effective communication. Again, I experienced a cultural nuance in expectation when working with an Asian family. Whilst they

42 Journal of Practice Teaching 5(3) 2004, pp.40-54 @ 2004. Whiting and Birch 
expected me to provide advice as the 'authority' in the matter, I expected them to be more talkative and active in exploring options in the care of a member of the family who had been diagnosed with a major mental illness. Respect for authority may result in passivity and silence and as Tsui and Schultz (1985) note, 'Long gaps of silence may occur as the client waits patiently for the therapist to structure the interview, take charge and thus provide the solution' (p.565). Erroneously concluding that the client has flat affect or is unmotivated are potential hazards if the practitioner fails to correctly interpret the often smallest cultural nuance in nonverbal cues.

Although a post modern stance provides philosophical underpinnings that embrace the phenomena of cultural diversity and cultural sensitivity, translating concepts into dynamic, evolving practice poses some critical questions. Differences and nuances create challenges to our balancing of professional obligation with expectation of service delivery and determinations regarding the distinction between client behaviour that is culturally appropriate and behaviour that is problematic.

\section{Some critical questions}

How can we ensure that we develop and maintain cultural sensitivity? What of the danger of cultural encapsulation? Can we develop culturally sensitive ethical guidelines and bring culturally appropriate interpretations to our work? How do we go about teaching about values and ethics in a multicultural context? These are some questions that both students and practitioners ask at teaching and learning forums.

In one sense, the only way to address such questions is to pose further questions that challenge our ways of thinking. To avoid cultural encapsulation and a practice that is infused with Western assumptions and values we need to use all our critical reflective abilities to deconstruct the sometimes narrowly prescribed ways of working. We need to pose questions that challenge known practice around (i) not giving advice and suggestions because it may foster dependency (ii) not taking a teaching role (iii) not accepting gifts from clients and (iii) not entering into dual or multiple relationships because establishing boundaries is important (Sue et al, 1998).

What if the encounter with a client from a different culture demands

43 Journal of Practice Teaching 5(3) 2004, pp.40-54 @ 2004. Whiting and Birch 
that you exhibit the expertise and authority that otherwise would be discouraged as qualities that magnify power differentials between you and your client? What if the client's view about mental illness, for instance, is based on beliefs regarding magic and witchcraft, however, they ask that you educate them on terminology and the biomedical point of view, so that they might understand what is being communicated to them? What if the client proffers a small gift and presses you to accept at your last session together? What if .... There are endless 'what if...' questions we might pose to challenge our ways of thinking and ensure greater cultural sensitivity.

Essentially, these crucial questions point to the logic of returning to the fundamentals.

Whenever I pick up the Australian Association of Social Work (AASW) Code of Ethics (2000), I'm struck by two competing thoughts:

1. it is an essential resource - a valuable document;

2. it is a prescriptive document that has little interpretive value and if followed to the letter, one would be unable to practice.

There is the ambivalence of feeling contented that I have a reference book and the frustration that I'm told so little when it comes to sticky situations.

This Code, along with the British, U.S. and Canadian codes, is necessarily a broad-based document which can offer guidance, but cannot and should not be relied upon to solve ethical dilemmas involving cultural issues.

These codes contain concepts and ideas that are well-known among helping professionals. Nevertheless, when considering culturally sensitive and ethical practice, one crucial question arises: How can abstractions within codes be interpreted? Subsequent key questions could be: What questions should we be critically reflecting upon to become aware of the power of cultural variables? Most importantly, how can we translate this awareness into behaviour leading to effective intervention?

I intend to work towards developing culturally sensitive ethical practice guidelines within the context of a multicultural society by firstly, assessing the cultural sensitivity of the ethics codes and secondly, balancing culture and ethical codes.

44 Journal of Practice Teaching 5(3) 2004, pp.40-54 @ 2004. Whiting and Birch 
Working towards culturally sensitive ethical practice in a multicultural society

\section{Assessing cultural sensitivity of the ethics code}

Professionals are expected to know and adhere to their ethics code. However, practitioners also need to demonstrate knowledge about their codes' sensitivity to diverse cultures. While codes have embedded within them requirements for cultural competence, for instance, in the Australian Association of Social Workers' Code of Ethics (2000) Section 4.2.4 is titled Cultural Awareness - how do some other principles fit with this?

For example, how do some cultural assumptions and expectations of our clients fit with ethics codes' statements regarding 'professional integrity'?

In the AASW Code of Ethics, Section 4.1.4 titled 'Professional Integrity' under (e) states: 'Social workers will ensure that professional relationships are not exploited to gain personal, material or financial advantage'. This sounds perfectly reasonable. But how does the practice of gift-giving to show appreciation to a practitioner fit with the principle of professional integrity as stated? There have been numerous occasions in my practice as a social worker when ethnic families have brought gifts to the final session. Does acceptance of such gifts, offered in the spirit of genuine appreciation, constitute some exploitative material gain? One supervisor had cautioned me about never accepting any gifts, taking an unqualified position. Another equally experienced supervisor had taken a much more relational position. Accepting the offered gift, in his view, turned on the 'it depends' argument. Cultural considerations might well be a dependent variable. Does accepting the gift suggest greater cultural sensitivity but less ethical practice or does rejecting the gift signify less sensitivity and greater adherence to ethical practice? Does a simplistic position of following the code to the letter make for good practice - culturally or otherwise? Perhaps the supervisor who recommended a 'it depends' position was suggesting a more balanced and measured approach, whereby cultural sensitivity was balanced with the spirit of, rather than the bald words, within a code of ethics.

Section 4.1.4 'Professional Integrity' includes under (g) cautions about dual relationships. Similar provisions appear in the BASW Code p. 7 under 3.4 'Integrity' 3.4.2 e 'To set and enforce explicit and appropriate professional boundaries to minimize the risk of conflict, exploitation or harm in all relationships with current or former service users, research participants, students, supervisees or colleagues.'

45 Journal of Practice Teaching 5(3) 2004, pp.40-54 @ 2004. Whiting and Birch 
Both these codes of ethics add a qualification to this statement which, in effect, softens the statement. This qualification relates to minimising the 'risk of conflict, exploitation or harm'. In the BASW Code p. 7 under 3.4.2.f states 'To avoid any behaviour which may violate professional boundaries, result in unintentional harm or damage the professional relationship.'

This qualification is important and in order to understand what professional integrity might look like in relation to cultural sensitivity, it is worthwhile considering a relatively familiar scenario for many practitioners.

Let's take as an illustration the example of an invitation extended to you by a client to attend a social event. This invitation may come unexpectedly from a client or family you have been seeing for some time. The client may be from an ethnic background which has a collectivistic culture and she thinks of you, as her social worker, as 'family'. She asks that you attend her granddaughter's christening celebration. She would be 'honoured' if you did so.

This invitation poses a dilemma for you as you consider a response that, on the one hand, conforms to ethical sanctions against dual relationships and, on the other, respects the client's genuine valuing of you within the context of her culture. In previous sessions, she has explained that her cultural context embraces multiplicity in relationship roles and that she has had her priest and her doctor to dinner. For this client, the notion of strict professional boundaries is not part of her culture.

The questions that might crowd your mind could be:

- Is there a real risk of harm or exploitation if I attend the social event?

- Do I risk harming the client/s if I attend?

- What decision, attending or not attending, would best respect the client's dignity?

- How can I respond in a way that reflects the client's worth as an individual?

(questions adapted from Pack-Brown and Williams, 2003)

Also crowding your mind might be ethical decision-making frameworks to assist in working through dilemmas. One such model, forwarded by Welfel (1998) proposes an ethical decision-making model that consists of nine steps:

46 Journal of Practice Teaching 5(3) 2004, pp.40-54 @ 2004. Whiting and Birch 
1. develop ethical sensitivity

2. define dilemma and options

3. refer to professional standards

4. search out ethics scholarship

5. apply ethical principles to the situation

6. consult with supervisor or respected colleagues

7. deliberate and decide

8. inform supervisor, implement and document actions

9. reflect on the experience

Such a model encourages the sort of critical questioning and reflection that offers the comfort of systemic analysis yet pushes the practitioner to consider the dilemma from several different perspectives (codes, scholarship and colleagues' views). Searching out ethics scholarship in this instance, would necessitate attention to diversity and difference and presuppose cultural sensitivity.

This framework implies balancing ethical considerations and for me, effective practice must have a balance.

\section{Balancing culture and ethical codes}

In this case of the invitation to a social event, an infant's christening, several responses are possible, not all of which are sensitive to both the client's culture and ethical principles. What are some of the options? What are their strengths and drawbacks?

Response 1

Explain to the client that your professional ethics code does not permit your participation in her social event. This is an example of a response emanating from a procedural perspective without consideration of the client's cultural context and practices. It would be fair to say that this response is not a culturally sensitive one. In fact, the client might be within her rights to beg the question, Who is protected here? The practitioner? The client? Both?

Response 2

Engage the client in discussion around the importance to her for you to

47 Journal of Practice Teaching 5(3) 2004, pp.40-54 @ 2004. Whiting and Birch 
attend. It might be argued that this response is more culturally sensitive than the first, however, it inherently questions the client's motives, suggesting to her that her request needs examination.

Response 3

Discuss with the client how she would feel if you did or did not attend. This response is similar to Response 2, suggesting that her request must be analysed. In addition, exploring her reactions to your options is premature and likely to confuse the client.

Response 4

Immediately accept the client's invitation to attend because you believe not doing so would offend the client and risk the professional relationship, which has been a long and positive one. This response, of immediate acceptance, might suggest that the practitioner has not carefully weighed the costs and benefits of agreeing to attend.

\section{Response 5}

Explain your dilemma to the client and tell her you wish to consult with colleagues, including someone from her ethnic background before you make a decision. In doing so, the practitioner positions the dilemma as one related to ethical constraints rather than to the client's request. This response considers the process of weighing cultural factors against ethical constraints. Nevertheless, by suggesting a consultation with an 'ethnic expert', the practitioner inherently questions the client's knowledge and understanding of what is appropriate.

\section{Response 6}

Share with the client that you feel honoured to be asked to such an important event in her life, but that her invitation presents a dilemma for you. This might be seen as a culturally sensitive statement because it positions the problem squarely in the practitioner's hands and shares the dilemma with the client, without demonstrating disrespect for the client's wisdom. This response might be followed by Response 3 .

In my practice, I have known professionals from many varied backgrounds to take very different positions on invitations to social events, particularly when the request has come from a client from a different cultural background. I have never seen any of them take the decision lightly

48 Journal of Practice Teaching 5(3) 2004, pp.40-54 @ 2004. Whiting and Birch 
and certainly, when I decided to not attend my client's granddaughter's christening, I deliberated carefully, sought my supervisor's opinion and spoke with colleagues before deciding that although there was very little risk of real harm to the client in my attending the event, doing so would extend boundaries beyond their professional perimeters. My discussion with the client acknowledged the importance culturally for her inclusion of me in such an event and my respect for her cultural position. However, our discussion also covered respect for different positions and the need for us to continue in roles that clearly indicated that our relationship was professional rather than friendly. Nevertheless, I have known other practitioners who have attended social events and argued that their need to be culturally sensitive was greater than their need to maintain clear professional role identity.

There are many other examples of the need to balance culture and ethical codes. Notions related to client welfare is one.

In the AASW code, Section 3.1 Value: Human Dignity and Worth states that the social work profession holds that 'each person has a right to well-being, self-fulfilment and self-determination, consistent with the rights of others'. The NASW (U.S.) contains an ethical principle valuing the 'inherent dignity and worth of the person.' Consistent with this value, social workers are required to 'treat each person in a caring and respectful fashion, (being) mindful of individual differences and cultural and ethnic diversity.' There is a similar provision in the BASW 3.1.2b p.4

Certainly, the overarching principle contained in these sections of various codes is protection of the welfare, or best interest, of the client. Nevertheless, these statements are broad and they leave room for interpretation and possibly, misinterpretation.

These codes, based as they are on principles of self-determination, individualism and clear relational boundaries, may well advocate a stance which is at odds with more interdependent, self-in-relation patterns of some ethnic and cultural ways of being. These contradictions may place practitioners in a bind - doing what is in the best interest of the client may conflict with various ethical codes. For instance, an Aboriginal woman with terminal cervical cancer rejected all forms of Western treatment in a large Sydney hospital and although not considered to be in her 'best interests' she insisted on discharging herself and going 'home' to her country community to be cared for by her extended family. For this Aboriginal woman, her self-determination could be

49 Journal of Practice Teaching 5(3) 2004, pp.40-54 @ 2004. Whiting and Birch 
seen to run counter to her best interests. However, she felt alienated in a big city hospital away from her family and her wish of 'going home' to be 'with family' was granted. In this case, the social worker and the team balanced ethical codes with culture and believed that the client would fare better in what she considered her own caring environment. The abstraction of 'best interests' needs careful consideration in such a case and self-determination regarding continuation or not of treatment viewed from different perspectives. Client welfare is not an obvious matter. Paradoxically, what appears to not be in the 'best interests' of the client, might in reality, be her 'best interests'.

Consider another situation. Clients from collectivist cultures for whom self-identity is inseparable from kinship systems may wish to bring family members with them to group therapy sessions. This may pose a problem for the professional in terms of the importance of maintaining the confidentiality of group members, yet the professional might understand that it is within the 'best interests' of the client to have the support they want. In this case, the professional must balance the rights of others and confidentiality with the expectation of different cultural groups and aim to negotiate a culturally sensitive decision. This notion of collectivity and support from family is raised by Pedersen (2000) who considers the concept of dependency as a potential source of conflict between ethical codes and culture.

In many diverse cultures, dependency on others is a way of life. Over time, cultural expectations regarding strong networks of interdependence have developed. Sometimes, socio-economic reasons have dictated that such interdependence is critical to the survival of many immigrants as well as indigenous people. Again a point of tension arises in that the ethics codes advise against relationships in which clients feel dependent on the professional. Perhaps several questions need to be asked to tease out the elements of the dilemma. Is it possible that a dependent relationship might be in the client's 'best interest' at least temporarily? Is it conceivable that a strong relationship with a professional might provide a sense of security and help the client, who feels they have little personal power, to build greater self-sufficiency? Again, paradoxically, the culturally sensitive practitioner might well be seen to be 'encouraging' dependency in order to help the client become more empowered eventually. Such tensions between individualism and collectivism and empowerment and dependency are common in work with people from diverse cultures and the ethical dilemmas they raise need careful

50 Journal of Practice Teaching 5(3) 2004, pp.40-54 @ 2004. Whiting and Birch 
reflection and logical consideration. A mere wish by the professional to be 'politically correct' is not enough, indeed, it runs counter to true professionalism, which requires that the professional be in a position to state clearly their dilemma and the reasons for their decision.

\section{A cautionary note}

There may be occasions when responding in a culturally sensitive manner may mean taking an historical view and working with its implications for clients in the contemporary context. For instance, an important consequence of oppression of indigenous and minority groups is the development of an intergenerational healthy cultural paranoia phenomenon (Ho, 1992; Paniagua, 1994; Smith, 1981). Amongst Australian Aboriginal people, for example, there is strong suspicion of professionals in official roles, particularly in relation to child welfare. Historically, welfare authorities routinely removed children from parents, a practice that has led to what is now known as 'the lost generations'. It makes perfect sense then, that Aboriginal people today might be distrustful of professionals who offer help, but are also in a position to recommend removal of children from families. Similarly, in the United States, this healthy paranoia phenomenon is evident amongst some African-American people who find it difficult to trust professionals who have disempowered them in the past (Smith, 1981).

However, the question might have to be asked: How do I determine the difference between client behaviour that is culturally appropriate and behaviour that is problematic? For instance, when does the healthy cultural paranoia exhibited by some oppressed cultural groups become problematic for them? Making that determination from a culturally sensitive stance is the challenge. 


\section{Some concluding thoughts}

Neither cultural encapsulation where the professional is trapped in one way of thinking and believing that theirs is the universal way, nor a keen sense of political correctness makes for culturally sensitive practice. The professional who wishes to be culturally sensitive and competent and have confidence in making culturally sensitive ethical decisions, needs to live with uncertainty and acknowledge the power of the postmodernist stance regarding the existence, and legitimacy of, multiple worldviews. At all times, such a practitioner is performing a delicate balancing act. They must be guided by and bring together into a coherent whole, ethical decision-making frameworks, what the ethics codes state, what the client says and believes and what the practitioner believes reflects a sincere practice, faithful to the spirit, if not the letter, of the code of ethics.

\section{References}

Australian Association of Social Workers (2000) Code of Ethics. Kingston. ACT. Australian Association of Social Workers

Christopher, J.C. (1996) Counseling's inescapable moral visions. Journal of Counseling and Development, 75, 17-25

Diaz-Lazaro, C.M., and Cohen, B.B. (2001) Cross-cultural contact in counselor training. Journal of Multicultural Counseling and Development, 29, 1, 41-56

Dominelli, L. (1988) Anti-racist Social Work: A challenge for white practitioners and educators. Basingstoke: Macmillan

González, R.C. (1997) Post modern supervision: A multicultural perspective. In D.B. Pope-Davis and H.L.K. Coleman (Eds.) Multicultural Counseling Competencies: Assessment, education and training and supervision. (pp.350-386) Thousand Oaks, CA: Sage

Goldberg, M. (2000) Conflicting principles in multicultural social work. Families in Society: The Journal of Contemporary Human Services, 12-21

Highlen, P.S. (1996) MCT theory and implications for organizations/systems. In D.W. Sue, A.E. Ivey, and P.B. Pedersen (Eds.) A Theory of Multicultural Counseling and Therapy. (pp.65-85) Pacific Grove, CA: Brooks/Cole

Ho, M. K. (1992) Minority children and adolescents in therapy. Newbury Park, CA. Sage 
Working towards culturally sensitive ethical practice in a multicultural society

Ivey, A. E. (1987) Reaction: Cultural intentionality: The core of effective helping. Counselor Education and Supervision, 26, 168-172

Ivey, A. E. , Ivey, M. B., and Simek-Morgan, L. (1997) Counseling and Psychotherapy: A multicultural perspective. Needham Heights, MA, Allyn and Bacon

Ivey, A.E., Pedersen, P.B., and Ivey, M.B. (2001) Intentional Group Counseling: A microskills approach. Belmont, CA: Wadsworth

Johnson, P. ((1989) Cross-cultural casework with the Indo-Chinese. Conference Proceedings, Australian Association of Social Workers Conference, Townsville, August, 36-38.

Nguyen, T., and Bowles, R. (1998) Counselling Vietnamese refugee survivors of trauma: Points of entry for developing trust and rapport. Australian Social Work, 51, 2, 41-47

Pack-Brown, S.P. and Williams, C.B. (2000) To discriminate or not to discriminate: Culture and ethics. Counseling Today. Alexandria, VA: America Counseling Association

Pack-Brown, S. P., Whittington-Clark, L. E., and Parker, W. M. (2002) Images of Me: A guide to group work with African-American women. Boston: Allyn and Bacon

Pack-Brown, S.P. and Williams, C.B. (2003) Ethics in a Multicultural Context. Thousand Oaks, CA: Sage

Paniagua, F. A. (1994) Assessing and Treating Culturally Diverse Clients: A practical guide. Thousand Oaks, CA: Sage

Pedersen, P.B. (2000) A Handbook for Developing Multicultural Awareness. (3rd ed.) Alexandria, VA: American Counseling Association

Smith, E.J. (1981) Cultural and historical perspectives in counseling Blacks.in D.W. Sue (Ed.) Counseling the Culturally Different: Theory and practice. (pp. 141-185) New York: John Wiley

Sue, Derald W. and Sue, D. (1977) Barriers to effective cross-cultural counseling. Journal of Counseling Psychology, 24, 5, 420-429

Sue, D.W., Ivey, A.E. and Pedersen, P. B. (1996) A Theory of Multicultural Counseling and Therapy. Pacific Grove, CA: Brooks/Cole

Sue, Derald W., Carter, R.T., Casas, J.M., Fouad, N.A., Ivey, A.E., Jensen, M., LaFromboise, T., Manese, J.E., Ponterotto, J.G. and Vazquez-Nutall, E. (1998) Multicultural Counseling Competencies. Thousand Oaks, CA: Sage

Sue, S. (1999) Science, ethnicity and bias: Where have we gone wrong? American Psychologist, 54, 2, 1070-1077

Sue, Derald W. and Sue, D. (2003) Counseling the Culturally Diverse. New York: John Wiley

53 Journal of Practice Teaching 5(3) 2004, pp.40-54 @ 2004. Whiting and Birch 
Thompson, N. (1997) Anti-discriminatory Practice. Basingstoke: Macmillan Tsui, P. and Schultz, G.L. (1985) Failure of rapport: Why psychotherapeutic engagement fails in the treatment of Asian clients. American Journal of Orthopsychiatry, 55, 561-569.

Welfel, E.R. (1998) Ethics in Counseling and Psychotherapy: Standards, research and emerging issues. Pacific Grove, CA: Brooks/Cole

Wohl, J. (1989) Integration of cultural awareness into psychotherapy. American Journal of Psychotherapy, 43, 3, 343-355. 